\section{Ingredientes de um prato exótico: saúde e alimentação em pauta no primeiro Congresso Médico Amazônico (Belém, 1939)}

\section{Ingredients for an exotic dish: health and diet on the agenda of the first Amazonian Medical Congress (Belém, 1939)}

\section{Aristóteles Guilliod de Miranda ${ }^{i}$}

Médico, Hospital Universitário João de Barros Barreto/ Universidade Federal do Pará. Belém - PA - Brasil

orcid.org/0000-0002-1052-9595 guilliod@gmail.com

\section{José Maria de Castro Abreu Jr.ii \\ "Médico e professor, Faculdade de Medicina/ Universidade Federal do Pará. Belém - PA - Brasil \\ orcid.org/0000-0001-8679-8890 jmcajr@gmail.com}

\section{Érico Silva Muniziii}

iii Professor, Faculdade de História/Universidade Federal do Pará. Bragança - PA - Brasil

orcid.org/0000-0002-5543-4266

ericomuniz@ufpa.br

Recebido em 19 mar. 2018

Aprovado em 10 abr. 2019.
MIRANDA, Aristóteles Guilliod de; ABREU JR., José Maria de Castro; MUNIZ, Érico Silva. Ingredientes de um prato exótico: saúde e alimentação em pauta no primeiro Congresso Médico Amazônico (Belém, 1939). História, Ciências, Saúde - Manguinhos, Rio de Janeiro, v.27, n.1, jan.-mar. 2020, p.219237.

Resumo

$\mathrm{O}$ artigo apresenta o contexto de organização e realização do primeiro Congresso Médico Amazônico, ocorrido na cidade de Belém, em agosto de 1939. Inserido na tradição da divulgação científica de seu tempo, o evento reuniu parte das elites médicas da região e contou com a participação de convidados reconhecidos nacional e internacionalmente, entre eles Josué de Castro e Dante Costa. Tendo como principais fontes os materiais impressos produzidos pelo congresso e as notícias veiculadas nos jornais paraenses, este texto examina a concentração de debates sobre as carências alimentares da Amazônia observando a compreensão acadêmica e política das faces do fenômeno para a região.

Palavras-chave: Congresso Médico Amazônico; congressos médicos; Dante Costa (1912-1968); Josué de Castro (1908-1973); Pedro Borges (1911-1978).

Abstract

The context in which the first Amazonian Medical Congress was organized and held in Belém, Brazil, in August 1939, is presented. Within the tradition of scientific communication of its time, the event brought together some of the region's medical elites and also had nationally and internationally renowned guest participants, including Josué de Castro and Dante Costa. Taking the printed matter produced by the congress and news stories printed in the local press as its main sources, this study examines the accompanying debates on dietary deficiencies in the Amazon, observing academic and political understandings of the different aspects of the phenomenon for the region.

Keywords: Amazonian Medical Congress; medical conferences; Dante Costa (19121968); Josué de Castro (1908-1973); Pedro Borges (1911-1978). 
A instituição dos congressos científicos se torna mais evidente a partir da segunda metade do século XIX, quando esteve associada às exposições internacionais comemorativas demonstrando o status de civilização vivenciado pelas nações desenvolvidas (Kuhlmann Jr., 2010). Na história da divulgação dos feitos das ciências no Brasil, serve de exemplo a exposição internacional de 1900, comemorativa dos 400 anos de descobrimento do país, quando uma série de eventos aconteceu na então capital federal, entre eles um evento médico (congresso de medicina e cirurgia). Tais momentos operavam, segundo Almeida (2010, p.200), como "mostras do otimismo e do enaltecimento da nacionalidade brasileira".

As exposições nacionais, internacionais (ou universais) e temáticas têm sido objeto de investigação na área de história das ciências ao longo dos últimos anos. Os estudiosos têm demonstrado que os vieses econômicos, a tutela do Estado e uma intenção ainda que difusa de "modernidade" marcaram a história desse tipo de exibição (Sanjad, 2017). Tais características costumam estar presentes também na historiografia que analisa os congressos médicos. Houve uma primeira tentativa de organizar um congresso dessa categoria profissional em 1878, em São Paulo, mas o evento não se realizou, sendo considerado o primeiro do tipo o congresso organizado pela Sociedade de Medicina e Cirurgia do Rio de Janeiro, em 1888 (Kuhlmann Jr., 2010).

A realização de congressos médicos, a partir do final do século XIX e início do século $\mathrm{XX}$, caracterizou uma estratégia de legitimação do conhecimento médico produzido diante dos pares, das autoridades públicas e da sociedade em geral, configurando os médicos como repositório do saber oficial da arte de curar (Almeida, 2006).

No estado do Pará não há relato de congressos antes do século $\mathrm{XX}$, posto que somente em 1914, com a fundação da Sociedade Médico-Cirúrgica do Pará (SMCP), é que os médicos de Belém conseguem de forma efetiva se organizar como classe, defendendo seus interesses, após algumas tentativas prévias que naufragaram por desavenças políticas (Miranda, Abreu Jr., 2014). Sendo assim, a primeira referência sobre congressos na região diz respeito ao primeiro Congresso de Médicos do Interior, realizado em Belém, em janeiro de 1939, e que consistiu em um evento coordenado pela Diretoria Geral de Saúde Pública do Estado (atual Secretaria Estadual de Saúde), restrito aos médicos que trabalhavam no interior do estado do Pará (Primeiro Congresso..., 24 jan. 1939). O primeiro congresso médico realizado no Pará em moldes mais contemporâneos aconteceu em Belém, também em 1939. Nas próximas páginas analisaremos o pioneirismo do evento na região amazônica e suas peculiaridades, que chamam a atenção para o modus operandi de elites médicas, as filiações nacionais e as representações de Amazônia colocadas pela medicina e por seus doutores. Por meio de jornais, discursos e atas, o congresso será o fio condutor para a análise do pensamento dos médicos acerca da alimentação na Amazônia.

\section{A organização e as "ausências confirmadas"}

Em 1939, a Sociedade Médico-Cirúrgica do Pará comemorava seus 25 anos de fundação. ${ }^{1}$ Em reunião dessa entidade, realizada dois anos antes, o médico Henrique Esteves propôs que a data fosse comemorada com a realização de um congresso no qual pudesse ser mostrada a pujança da agremiação, levando "a todos os ângulos do país a expressão de mais 
alta cultura médica paraense" e também para "tornar conhecidos ao nosso erudito meio médico colegas de maiores, porém afastados centros da medicina brasileira", promovendo, dessa maneira, a defesa da integração profissional e a discussão de assuntos que mais de perto interessavam à região amazônica (Primeiro Congresso..., 9 jul. 1939).

As notícias veiculadas na imprensa são entendidas aqui como parte do cotidiano da cidade de Belém e como uma amostragem de como o jornalismo local interpretou a importância do evento no bojo das elites locais. Seguindo a perspectiva de uma história "por meio da imprensa", como sugere Luca (2005, p.111), atentamos nas armadilhas para não essencializar os fatos históricos. O trabalho com fontes periódicas deve colaborar para o campo de uma história política renovada. Segundo Figueiredo (2005), o grande número de jornais, gazetas, folhetos e panfletos havia justamente marcado o período de ápice da comercialização da borracha no mercado internacional. Mais de trezentas publicações de diferentes tendências circulavam no Pará na virada do século XIX para o XX, entre elas diversos boletins de associações comerciais, profissionais e médicas que haviam se instalado na capital do estado naqueles anos.

A profusão de notícias sobre o congresso marcou o cotidiano da imprensa local. Pelos discursos e notícias publicadas, percebe-se que, para a sociedade médica paraense, a realização daquele evento representava um reposicionamento da classe no cenário nacional, alavancando uma visibilidade que o estado do Pará havia perdido após o final do "ciclo da borracha", entrando em um período que Weinstein (1993, p.241) denominou a longa decadência. A história da circulação de capitais na cidade de Belém, advindos da Belle Époque na Amazônia, justifica inclusive a implementação de políticas de controle social, dando origem a um processo disciplinar que teve amparo nas ciências médicas (Sarges, 2000). Segundo Fábio Castro (2010), o impacto desse período para a história e suas consequentes nostalgias dos tempos de glória orientam ainda a memória coletiva e a própria narração da temporalidade dos fatos históricos da capital paraense. Dessa forma, parte da memória e da historiografia da região amazônica passou a ser permeada pela brevidade do "tempo da borracha" (Daou, 2004).

Assim, a ideia de um congresso comemorativo o jubileu de prata da agremiação não poderia ficar no esquecimento, considerando a importância que a entidade associativa médica possuía junto à comunidade científica de Belém. Mais ainda para determinado membro da diretoria da instituição - Pedro Borges (1911-1978) -, aquela ocasião não poderia ser desperdiçada. E, embora fosse apenas o segundo secretário da agremiação médica, viu ali uma oportunidade imperdível de levar avante seus planos pessoais. Para o secretário, a finalidade do congresso era a discussão dos "problemas médicos sociaes da Amazônia" (Primeiro Congresso..., 14 jul. 1939). Desse modo, Pedro Borges levou ao presidente da entidade, o médico João Prisco dos Santos, a sugestão de um congresso, ficando responsável por sua organização. O presidente, no entanto, não ficaria como figura decorativa quanto à gênese do evento. Médico conhecido, catedrático da Faculdade de Medicina do Pará, político com mandato (Meira, 1986, p.263), logo o doutor Prisco seria convocado pela imprensa para falar sobre o congresso, sinônimo de pujança da Sociedade Médico-Cirúrgica e, consequentemente, do grau de desenvolvimento da medicina paraense (Primeiro Congresso da Amazônia, 7 jul. 1939). 
O evento se pretendia grandioso: "o primeiro na sua especialidade que se realiza no Norte" (O Brasil..., 17 ago. 1939). Sua organização demandaria um tempo razoável. Tanto que, em janeiro de 1939, a Sociedade Médico-Cirúrgica do Pará tomou as primeiras medidas convocando uma assembleia geral extraordinária na qual, entre os assuntos a ser discutidos, constava o "primeiro Congresso Médico" (Sociedade..., 20 jan. 1939). Não se tem registro dos desdobramentos dessa reunião, e somente em julho de 1939 surgem notícias sobre a oficialização do congresso e a liberação de verba pelo interventor federal (Primeiro Congresso..., 10 jul. 1939). Segue-se um discurso do secretário-geral do estado, doutor Deodoro de Mendonça, a convite do presidente da SMCP, Prisco dos Santos, "para iniciar, pelo microfone da Rádio Clube do Pará, a propaganda do primeiro Congresso Médico Amazônico" (Primeiro Congresso..., 16 jul. 1939b).

Dizendo-se leigo nas questões científicas da iniciativa, Deodoro falou da importância do congresso como uma circunstância de um "despertar auspicioso dos homens de inteligência e saber" frente aos "problemas da natureza e do homem que habita o vale imenso do Amazonas", principalmente a saúde, responsável pelo fracasso de "todas as tentativas de civilização do vale". O congresso marcaria "um ponto luminoso na história da raça e da economia brasileira". Ainda segundo Deodoro, os assuntos a ser debatidos "comportarão o estudo de tudo quanto pensamos, sentimos e precisamos no terreno da saúde" (Primeiro Congresso..., 16 jul. 1939b).

O prefeito Abelardo Conduru também fez um pronunciamento radiofônico "na obra de propaganda do primeiro Congresso Médico Amazônico" dias depois do secretário de governo. Falou sobre a importância do evento, evidência de que o Pará, "dia a dia, mais se alevanta" rumo ao progresso, inclusive o científico, sendo o congresso "a maior e melhor expressão concreta dessa verdade", o passo inicial na conquista da saúde para o homem e da salubridade para a "planície imensa, ignorada, misteriosa cujos problemas magnos, pela primeira vez defrontarão vontades resolutas". E segue-se o texto laudatório, ufanista, bem ao gosto das autoridades em todos os tempos, com espaço para uma cutucada no "caboclo humilde, modesto e às vezes ignorante (sofredores estoicos)", de quem não se poderia esperar "esforços para vencer os males que nos afligem, na angustiosa situação em que vivemos" (Primeiro Congresso..., 28 jul. 1939).

A fala do prefeito, ainda que cheia de esperança, encerrava uma concepção comum no início do século XX, a ideia da Amazônia descrita por Euclides da Cunha (1999, p.71), um lugar de uma natureza de "opulenta desordem", onde o homem era "um intruso impertinente", totalmente refém dos caprichos do meio ambiente que o cercava, mas que poderia ser libertado pela intervenção da ciência. Segundo Pacheco (2009), a figura do caboclo foi construída ao longo da história, culpabilizando as populações afroindígenas da Amazônia pelas precárias condições de saúde da região. Tal concepção, herdeira das descrições de viajantes e naturalistas, ganhou outro tom em meados do século XX, à luz das intervenções ilustradas que a ciência médica propunha à época.

Esse tipo de leitura sobre a região vivenciou novo enquadramento a partir do fim dos anos 1930, quando outro sentido passou a ser atribuído à Amazônia pelo Estado Novo. Projetos como a Marcha para o Oeste, lançado em 1938, e posteriormente a viagem de Getúlio Vargas à região, em 1940, demarcaram novo momento da busca pela integração econômica nacional 
(Andrade, Hochman, 2007; Andrade, 2010). Foi nesse novo contexto que, durante todo o primeiro semestre de 1939, convites foram enviados aos quatro cantos do país na tentativa de tornar o congresso um evento sem precedentes, capaz de apresentar soluções para os problemas da Amazônia. Segundo o jornal Estado do Pará, era prevista a participação de "nomes de relevo no mundo médico brasileiro, vindos dos vários pontos do país" (Primeiro Congresso..., 16 jul. 1939a). Todos os estados foram convidados, "tendo quase todos, num eloquente atestado de cordialidade, hipotecado solidariedade a tão nobilitante realização" (Primeiro Congresso..., 9 ago. 1939), mas que não resultou em efetiva participação. Na prática, o congresso contou apenas com integrantes dos estados do Amazonas, Maranhão, Ceará, Pernambuco e do Distrito Federal. ${ }^{2}$ O médico paraense Epílogo de Campos, representante da comissão organizadora do congresso no Rio de Janeiro, manifestou-se ao jornal Correio da Noite, daquela cidade, pela necessidade da efetivação do evento, "para que possam os valores médicos do Pará e Amazonas unificar bases sólidas e definitivas para a solução dos magnos problemas sanitários locais" (Um médico..., 26 jul. 1939).

Essa importância da região surge nas comunicações dos organizadores do congresso; no entanto, várias foram as dificuldades de transporte para a capital paraense - cujo acesso ainda se fazia prioritariamente por via marítima -, e a distância do Sul/Sudeste; a precariedade da aviação comercial (muitas vezes ainda utilizando hidroavião), particularmente para o Norte do país. Vale ressaltar que a companhia aérea Sindicato Condor oferecia $50 \%$ de desconto nas passagens, desde que fossem compradas ida e volta (Correspondência..., 8 ago. 1939), e que o Loide Brasileiro dava desconto de 30\% nas passagens de navio para Belém, ficando a hospedagem por conta da organização do congresso, com verbas liberadas pelo governo do estado (Primeiro Congresso..., 28 jun. 1939), ${ }^{3}$ em mais uma iniciativa do governo do Pará, que oficiara ao ministro da Educação para que esse ministério solicitasse às empresas de transporte a redução de $50 \%$ no custo das passagens aos congressistas (Congresso Médico..., 13 jul. 1939, p.10).

Durante o evento, em agosto de 1939, como visto, poucos estados mandaram delegações, e mesmo profissionais que haviam se comprometido em participar do simpósio, como Waldemar Berardinelli, catedrático da Faculdade Nacional de Medicina e presidente da Sociedade de Medicina e Cirurgia do Rio de Janeiro; Peregrino Jr., ${ }^{4}$ médico e jornalista que morara alguns anos em Belém, onde iniciara seus estudos médicos; Manuel de Abreu, criador do método de abreugrafia; 5 e Ary Miranda, eminente tisiologista brasileiro que presidiu o primeiro Congresso Nacional de Tuberculose, enviaram suas felicitações pelo empreendimento e as justificativas por suas ausências aos organizadores do congresso. $\mathrm{O}$ médico Souza Macedo, em artigo de divulgação do evento, chegou mesmo a informar que o famoso médico Clementino Fraga, professor catedrático de clínica médica da Faculdade Nacional de Medicina, do Rio de Janeiro, e membro da Academia Brasileira de Letras, já havia confirmado sua presença em Belém (Primeiro Congresso..., 14 jul. 1939). No entanto, quando o congresso teve início, a imprensa publicou o telegrama de Clementino Fraga, somando-se assim às outras personalidades que se tornaram "ausências confirmadas" ( $O$ primeiro Congresso..., 12 ago. 1939).

$\mathrm{O}$ aparente desinteresse de expoentes nacionais convidados para com um congresso que pretendia chamar bastante atenção para a região amazônica também se fez sentir nas 
esferas locais, uma vez que, pela leitura dos periódicos, também é possível sentir a ausência de médicos paraenses na abertura do evento, como se depreende da fala de um participante, representante do Centro Médico Cearense, denunciando que o congresso ainda não tinha provocado "o entusiasmo e o interesse que eram de esperar não apenas do povo que vem assistindo indiferente à organização do certame... mas a própria classe médica, que parece não vibrar uníssona para que ele tenha repercussão e o brilho..." que merecia (O primeiro Congresso..., 12 ago. 1939).

De fato, mesmo o médico paraense Souza Macedo, ainda na fase de organização do evento, queixava-se de que Belém, que era sede de uma faculdade de medicina e possuía uma classe médica numerosa e vários estabelecimentos hospitalares, não poderia continuar nesse "indiferentismo enervante". A ideia do congresso, portanto, era magnífica, mas muito arrojada para o meio, dada "a má vontade existente entre a classe médica paraense em relação a esses objetivos” (Macedo, 14 jul. 1939). Essas queixas de desinteresse dos esculápios paraenses não parecem ligadas especificamente ao congresso, posto que o mesmo problema foi relatado durante a fundação do Sindicato Médico Paraense, associação criada na mesma década (Miranda, Abreu Jr., 2015).

\section{As marcas da modernidade}

A sessão de instalação, no Theatro da Paz às 21h, foi retransmitida pela Rádio Clube do Pará e filmada pelo “técnico cinematográfico Libero Luxardo, diretor da Lux-Film!" (A instalação..., 11 ago. 1939). Desse filme nada mais se soube.

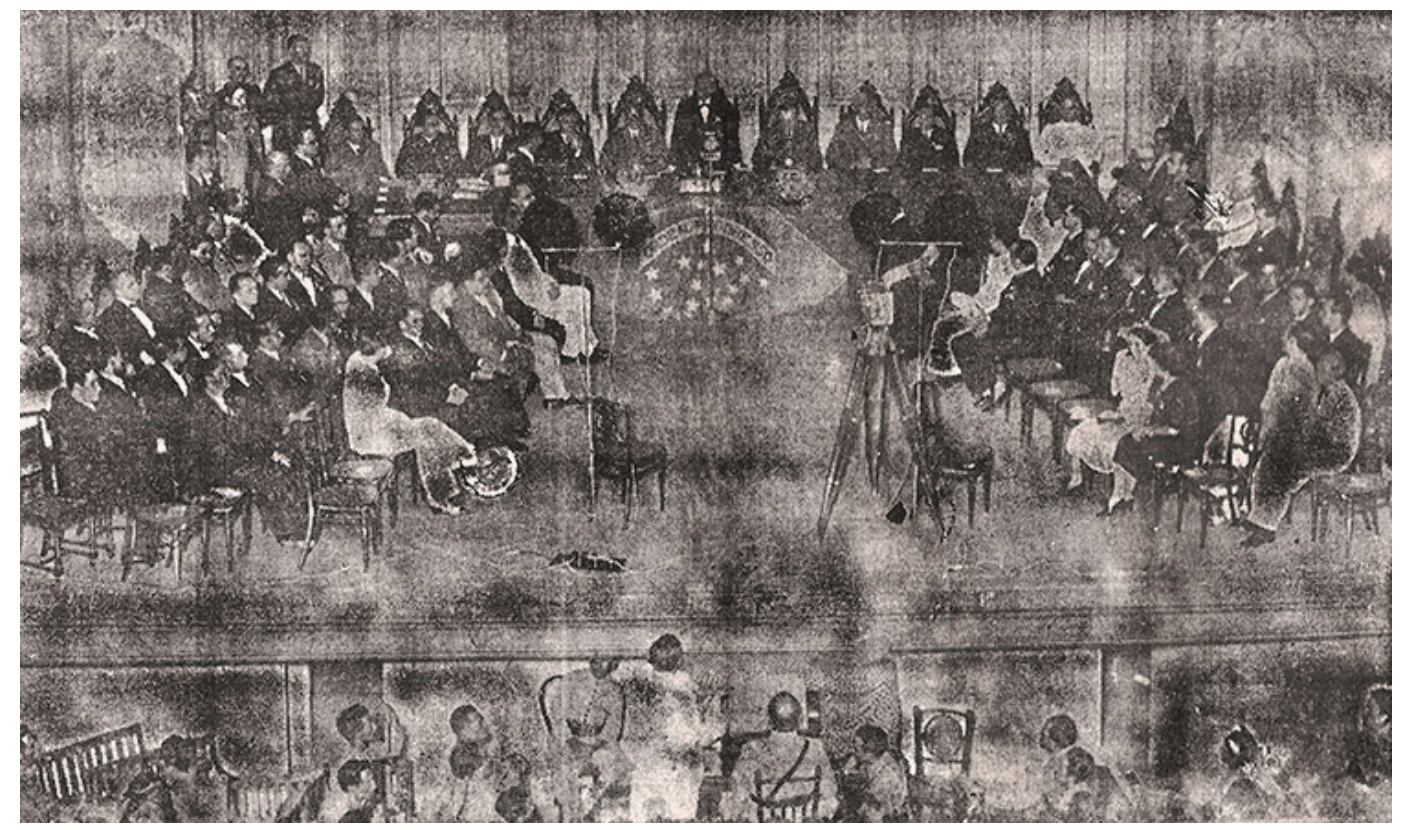

Figura 1: Mesa geral que presidiu a cerimônia de instalação no Theatro da Paz (Folha do Norte, 11 ago. 1939, p.1) 
Por esses elementos pode-se avaliar a importância que os organizadores buscaram imprimir ao evento, envolvendo-o com uma aura do que havia de moderno ou representativo. A Rádio Clube do Pará, criada em 1928, foi a primeira emissora da Amazônia, e, já na década de 1930, o rádio era um veículo que tinha adquirido uma importância política, como um formador de opinião; além disso, era um momento em que a "Clube" vivia uma fase de expansão (Vieira, Gonçalves, 2003, p.46; Costa, 2015, p.22). Ligar um congresso a essa tecnologia era fazer com que seus debates ultrapassassem as fronteiras do estado e da própria classe médica, corroborando as ideias de Edgard Roquette-Pinto - médico e antropólogo carioca precursor na difusão das emissões radiofônicas no Brasil -, muito em voga no período, de que o rádio deveria servir como uma verdadeira escola popular, propagando ciência e cultura entre todos os brasileiros analfabetos (Sá, 2006, p.175).

Construído em 1878, o Theatro da Paz, em 1939, definitivamente não era uma representação da modernidade. A casa de espetáculos era uma herança patrimonial do período de expansão da economia da borracha na Amazônia, quando a capital do Pará passou por uma intensa e contínua remodelação do seu espaço urbano, entre outros aspectos científicos, tecnológicos, políticos e sociais, que muito influíram na ordenação da cidade no século XIX (Souza, 2010, p.39). Por um lado, se ali não estava uma arquitetura propriamente moderna, era a melhor edificação existente na cidade para a realização de um congresso, não somente pelo espaço de alta significação social, mas por transmitir uma ideia de civilização local com padrões culturais elevados.

Quanto ao uso do cinema, este já era bem conhecido pelas elites amazônicas para divulgação de seus feitos desde os primórdios dessa novidade. Assim sendo, os organizadores do congresso contrataram o cineasta de Sorocaba Líbero Luxardo (1908-1980), que, entre muitas produções, havia feito um longa-metragem institucional para o médico Mário Kroeff, mostrando os avanços da medicina no combate ao câncer. Líbero desembarcou em Belém em 1939, "com uma cópia de seu maior sucesso, Alma do Brasil (1931-1932), e disposto a fazer cinema na Amazônia" (Veriano, 1999, p.27). Radicando-se em Belém, construiu um estúdio e produziu diversos cinejornais, curtas, longas, ficções e documentários de caráter regional, enveredando também pela carreira política no Partido Social Democrático (PSD), como deputado estadual (Autran, 2008, p.12). Filmar o congresso foi uma oportunidade para apresentar seu trabalho à sociedade paraense. Afirma Veriano (1999, p.28), sem precisar o ano, que "de uma feita, na minha presença, resolveu destruir todo o seu acervo de documentários afirmando repetidas vezes que 'velharia não serve pra nada'". Certamente a documentação cinematográfica referente ao congresso deve ter desaparecido nesse contexto.

Um fato inusitado: o congresso acabou contando com um participante internacional: o doutor Marshall A. Barber, malariologista da Fundação Rockefeller, "talvez o maior nome, nos círculos científicos dos Estados Unidos, senão do Universo, na sua especialidade", segundo o articulista do jornal Folha do Norte. O festejado cientista, aproveitando as poucas horas em que permaneceu em Belém, proveniente do Nordeste, antes de retornar para os EUA, visitou o Instituto de Patologia Experimental do Norte (hoje, Instituto Evandro Chagas) e à noite, "especialmente convidado", compareceu à sessão do congresso. Convidado pelo médico Evandro Chagas, representante do Instituto Oswaldo Cruz no congresso, chefe da Comissão de Estudos das Grandes Endemias do Brasil e responsável pela organização inicial 
do Instituto de Patologia Tropical paraense, fez parte da mesa dos trabalhos no Theatro da Paz. ${ }^{6}$ Dirigindo-se em inglês à assistência, o cientista norte-americano se manifestou, declarando-se honrado em participar do evento e lamentando seu desconhecimento da língua portuguesa, o que permitiria uma maior interação (Notável cientista..., 14 ago. 1939).

A presença inesperada do cientista à sessão do congresso foi notícia no jornal carioca Correio da Manhã, que destacou o fato dizendo que o doutor Barber fora convidado especialmente para o evento, tendo discursado em inglês, dizendo-se honrado com o convite e por se achar diante de uma assembleia de médicos ilustres, e que lamentava desconhecer a língua portuguesa, não podendo assim exprimir seus sentimentos (Para o Congresso..., 15 ago. 1939). Notícia com o mesmo teor é reproduzida pelo Jornal do Brasil, também do Rio de Janeiro (Notícias..., 15 ago. 1939). Provavelmente o correspondente jornalístico, ao repassar para as agências de notícias a presença do cientista americano em Belém, amplificou sua efetiva participação no conclave científico. A ideia devia ser mesmo esta: adicionar grandiosidade a tudo o que se referisse ao evento, mesmo que fosse um convite fortuito a um médico estrangeiro de passagem pela capital.

\section{Saúde e alimentação na Amazônia na agenda do Congresso Médico Amazônico}

O primeiro Congresso Médico Amazônico foi pensado sobre quatro temas centrais: lepra, impaludismo, alimentação e mortalidade infantil. ${ }^{7}$ Por conta do desdobramento do temário principal e do número de trabalhos encaminhados à organização, houve a necessidade da realização de plenárias extraordinárias em outros horários que não o noturno, reservado para as sessões ordinárias.

Debater as doenças acima citadas, acrescidas da tuberculose, assunto de plenárias específicas, era o que se esperava em um congresso médico na Amazônia daqueles anos, tão alarmantes os índices epidemiológicos das mencionadas patologias, em tempos de uma medicina campanhista e com uma abordagem verticalizada sobre o combate às doenças (Fonseca, 2007). Essa concepção era herdeira das políticas higienistas na capital paraense das primeiras décadas do século XX. Henrique e Amador (2016) demonstraram que esse período foi marcado pela busca em superar vícios e a degeneração da raça por meio de medidas como o combate às doenças venéreas; medidas essas que haviam sido viabilizadas pela criação do Instituto de Profilaxia da Lepra e das Doenças Venéreas na década de 1920.

O que chamava a atenção no programa eram os temas alimentação e mortalidade infantil. Este seria o diferencial do congresso: mostrar a importância da nutrição para a saúde, cujos estudos na América Latina começavam a ser divulgados e ganhavam novos adeptos (Vasconcelos, 2010, p.937), sendo considerado o marco inicial, no Brasil, o primeiro inquérito brasileiro sobre alimentação, realizado junto a trabalhadores do Recife em 1932 por Josué de Castro (Bizzo, 2012, p.17). Marcado pela presença de médicos com trabalhos importantes nessa área, destacavam-se entre os congressistas o já citado Josué de Castro, bem como Dante Costa, esses os mais conhecidos nacionalmente, Pedro Borges, o idealizador, além de figuras como Araújo Lima, Adriano Jorge Ramayana de Chevalier, entre outros. Torna-se, pois, interessante conhecer um pouco mais sobre os principais participantes do congresso. 
As biografias médicas são entendidas de maneira articulada aos seus contextos, ou seja, na busca das relações e dos trânsitos acadêmicos de uma geração de especialistas que exercem funções intelectuais (Levi, 1996). Não se trata, portanto, de abordar as vidas dos médicos como compêndio de fatos heroicos ou curso que caminhe para uma história laudatória ou pouco crítica, caindo na armadinha da biografia oficial, isolada de um campo social, baseada em uma sucessão de fatos agrupados cronologicamente, muitas vezes criando uma ideia de predestinação (Bourdieu, 2006).

Entre as consideradas "estrelas do evento", destacava-se Josué Apolônio de Castro (1908-1973), nome que à época já era referência na atuação no combate à fome e à miséria brasileiras, o que lhe rendeu reconhecimento internacional, mas também problemas com o governo brasileiro pós-1964 (Andrade, 1997; Andrade et al., 2003). Nascido no Recife, em 1908, graduou-se em medicina na Faculdade Nacional de Medicina do Rio de Janeiro em 1929. Retornou para Recife passando a fazer parte da recém-fundada Faculdade de Medicina, onde defendeu a tese de livre-docência O problema fisiológico na alimentação. Logo nos primeiros anos de formado, entendeu que a fome estava presente na vida de grande parte da população brasileira. Sua obra Geografia da fome, publicada em 1946, tornou-se um clássico de grande repercussão político-social, que afirmava não ser a fome um problema natural, mas fruto de ações dos homens, de suas opções, da condução econômica que davam a seus países (Andrade, 1997). Josué de Castro, além da participação efetiva nas plenárias do congresso debatendo os temas apresentados, discursou na abertura e no encerramento do evento, quando destacou a importância da compreensão dos aspectos sociais da ciência e o fato de que dessa compreensão "só poderá nascer alguma coisa de nobre, de útil e de grande para o Brasil" (Como decorreu..., 16 ago. 1939, p.5).

A impressão de Josué de Castro ao retornar ao Rio de Janeiro foi assim descrita nas páginas do jornal Folha do Norte:

Trago do Congresso Médico Amazônico, reunido em Belém, a melhor das impressões. Não foi este certame científico um simples ensejo para se fazer conhecimentos e amizades. Foi muito mais do que isso. Foi uma ótima oportunidade para que um grupo de médicos - identificados com os problemas da vida da Amazônia - corporificasse num programa exato quais as medidas e iniciativas a tomar para a defesa do elemento humano, que é nesta região, mais do que qualquer outra no mundo, o eixo de suas possibilidades econômicas e de sua evolução social. Nos poucos dias que estive no Pará, senti a inquietação intelectual dos jovens em busca de diretrizes para a sua atividade transbordante de desejo de atuar e, também, senti o desejo ardente dos dirigentes de realizar com acerto algo importante em beneficio da coletividade. Ora, os ensinamentos divulgados e os rumos traçados por este Congresso servirão de balizas para toda uma série de iniciativas do mais alto alcance social, seja no terreno da pura especulação científica, por despertarem a atenção dos estudiosos locais para certos problemas merecedores de estudo, seja no campo da realidade administrativa, por permitirem aos poderes públicos que realizem medidas que venham de encontro às necessidades reais da região e em moldes que se tornem realmente eficientes para a solução de cada problema (Ainda o congresso..., 7 set. 1939, p.6).

Nesse depoimento, Josué de Castro ratifica o tipo de intervenção que vinha defendendo ao longo de sua trajetória, a necessidade de parâmetros acadêmicos para lidar com os 
problemas alimentares amazônicos. Nessa perspectiva, somente via pesquisa científica o estado seria capaz de corrigir os "desajustes" e conhecer as necessidades reais da região, reforçando a concepção de que a "salvação" da Amazônia era possível por meio da ciência.

O segundo participante de destaque no congresso é Dante Nascimento Costa (19121968), mais conhecido como Dante Costa. Nascido em 1912, filho de tradicional família paraense, seu pai era o escritor e arqueólogo Angyone Costa, autor de estudos sobre a cultura indígena brasileira (Frota, 2011, p.32-36). Dante era um "paraense que brilha no Sul", epíteto que durante muitos anos fez a alegria das incipientes colunas sociais das décadas de 1930 a 1960 nos periódicos de Belém. Tendo sua família se transferido para o Rio de Janeiro, Dante cursou medicina na Faculdade Nacional, graduando-se em 1934. Costa foi um dos pioneiros na ciência da nutrição no Brasil, conquistando destaque internacional com obras voltadas para essa área do conhecimento. Transitando entre a medicina e a literatura, teve também participação ativa na vida literária brasileira, publicando livros de contos, relatos de viagem, traduções etc., além de intensa colaboração em jornais (Frota, 2011). É descrito pelos jornais de Belém como "jovem representante do Distrito Federal, promissora esperança de cientista", "da Divisão de Amparo a Maternidade e a Infância, do Ministério da Educação e Saúde" e representante de Sociedade de Medicina e Cirurgia do Rio de Janeiro (Notas..., 18 ago. 1939). Na área médica, influenciado pelos trabalhos de Josué de Castro, dedicou-se às questões da alimentação/nutrição sendo autor de importantes obras nesse campo.

Em publicação um ano antes do evento de Belém, Costa sintetizou parte de suas ideias sobre os hábitos alimentares encontrados na Amazônia na obra Bases da alimentação racional (Muniz, 2015). No livro, o médico lista os costumes à mesa das populações da Amazônia da seguinte maneira:

Quanto ao caboclo do Pará e do Amazonas, come pirarucú, peixe, aliás, de certo valor proteico, e toma chibé. Chibé é uma porção de farinha d'água em um copo d'água açucarada - alimento zero, que nada nutre, que só dá calorias. E as proteínas? E as gorduras? E as vitaminas e os sais? (Costa, 1938, p.215).

Durante o congresso médico, discursou na abertura e também proferiu palestra sobre alimentação na Amazônia, "elaborada em estilo claro, elegante, persuasivo", baseada em "dados estritamente científicos". Ao final fez a defesa da educação alimentar e conclamou a que se ensinasse o povo a se alimentar, "para o engrandecimento do Brasil" (Encerra-se..., 15 ago. 1939). As ideias debatidas por Dante Costa (Figura 2) sobre o regime alimentar na Amazônia dariam origem anos mais tarde à publicação Saúde, alimentação e pobreza na Amazônia, em que abordaria temas como o marasmo das populações da floresta e a pobreza de nutrientes encontradas na região (Costa, 1965). Assim, parte da culpa do problema alimentar recaía sobre os hábitos alimentares das populações ribeirinhas da região, por vezes revestidas de exotismo pelos parâmetros da ciência. 


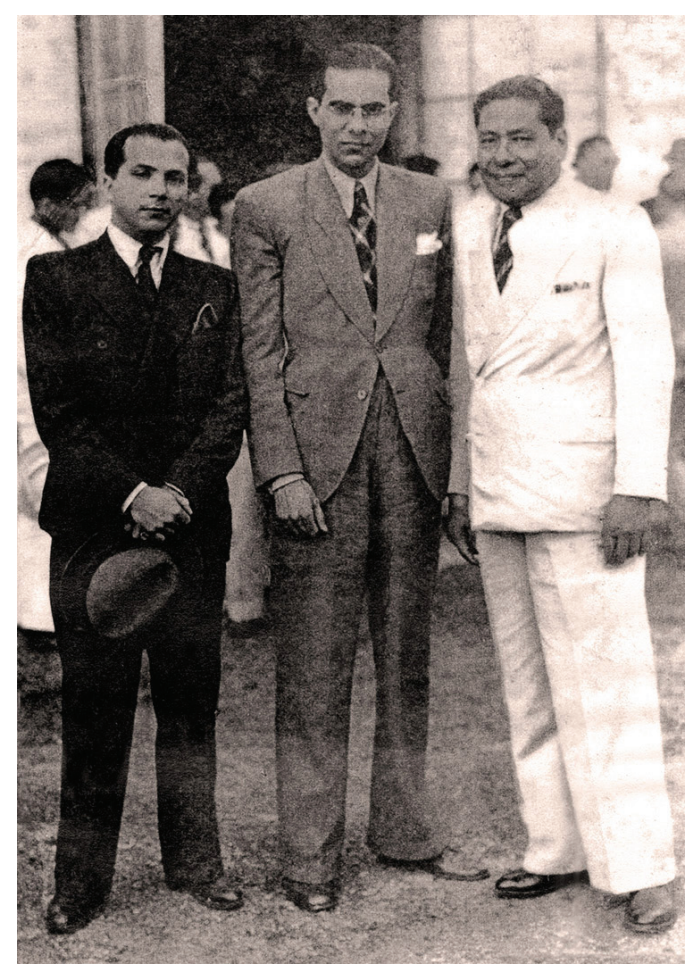

Figura 2: Dante Costa e Josué de Castro (ao centro) ao lado do jornalista da Folha do Norte José Santos (de branco) em foto tirada quando chegavam para o congresso (Folha do Norte, 11 ago. 1939, p.1)

O terceiro nome que ganhou destaque entre os participantes do evento foi Pedro Borges (1911-1978). Pedro Lago da Costa Borges ingressou em 1930 na Faculdade de Medicina e Cirurgia do Pará, transferindo-se posteriormente para a Faculdade de Medicina da Bahia, onde se diplomou em 1935. Mais tarde realizou cursos de especialização em serviços de nutrição na Argentina, retornando em seguida ao Pará, onde prosseguiu com suas pesquisas relacionadas à alimentação. Alguns anos após o congresso médico, foi convidado a organizar os serviços públicos de saúde do recém-criado território federal do Amapá. Por motivo de saúde, transferiu-se para o Rio de Janeiro, passando a integrar a equipe do Instituto de Nutrição da Universidade do Brasil, que era dirigido por Josué de Castro. Mais tarde, Pedro Borges chegaria à direção do mencionado instituto (Meira, 1986, p.319322). Sua participação, tanto na organização do congresso quanto na exposição de seus trabalhos "O mapa da alimentação na Amazônia" e "Frequência e letalidade do beribéri na Santa Casa do Pará no período de 1889 a 1938", dentro do tema oficial "O problema da alimentação na Amazônia", sensibilizaria o prefeito de Belém, Abelardo Conduru, que criaria a Diretoria de Alimentação Pública Municipal.

Pedro Borges foi o grande idealizador do congresso. Bastante apropriada é a opinião do escritor e jornalista Jacques Flores ao dizer que Borges é "o terçado de dois gumes que abriu o cerrado da descrença, do indiferentismo local, para que resultasse o clarão que já agora é beleza e é verdade", podendo enfim concretizar "o teu maior sonho de moço e de idealista, filho da gleba: o $1^{\circ}$ Congresso Médico" (Parabéns..., 13 ago. 1939). 
Se esses três nomes já seriam suficientes para expressar a importância do congresso para os estudos sobre alimentação, outros participantes merecem ser relacionados, como por exemplo, Adriano Jorge, Araújo Lima e Ramayana de Chevalier, pelo Amazonas.

José Francisco de Araújo Lima (1884-1945) era paraense radicado no Amazonas e formado em medicina na Bahia. Além da atividade como político, publicou vários livros, entre eles, Amazônia, a terra e o homem, hoje considerado um clássico nos estudos de sociologia da Amazônia (Pontes, Pontes, jul.-dez. 2015). Adriano Augusto de Araújo Jorge (1879-1948) era alagoano, formado na Faculdade de Medicina da Bahia e radicado no Amazonas; além de sua atividade política, foi um intelectual preocupado com a questão social do homem amazônida e ficou conhecido como o "médico dos pobres", por atender gratuitamente as pessoas em seu consultório (Câmara Municipal..., [1975?]).

Walmiki Ramayana Paula e Souza de Chevalier (1909-1972), formado em medicina na Bahia, foi também um intelectual de destaque, autor de No circo sem teto da Amazônia, sobre o drama social dos seringais, que tal como $A$ selva, de Ferreira de Castro, figura entre os livros que buscam revelar o "outro lado" da Amazônia (Kruger, 2001, p.11).

Alfredo Duailibe, Clodomir Millet e Antonio Pires Ferreira compunham a delegação do Maranhão. Duailibe, além da carreira política, atuou na área da educação como professor universitário, e, mais especificamente, no que se refere à nutrição e educação física. Millet escreveu o livro A alimentação no norte do Brasil, e Antônio Pires Ferreira foi um dos fundadores da Faculdade de Medicina do Maranhão. Escreveu A luta contra a tuberculose no Maranhão.

A delegação cearense era composta por Cesar Cals, Walter Porto, Alberto Leite e Jurandyr Picanço (os dois últimos, paraenses), professores e tisiólogos nos sanatórios cearenses, cujos trabalhos estavam direta ou indiretamente relacionados ao tema da alimentação, por meio de livros, palestras, pesquisas etc.

Em verdade, a maioria dos participantes tinha certa ligação com a questão nutrição/ alimentação na região. Alguns pelo fato de terem convivido em suas faculdades com colegas que viriam a trabalhar o tema; outros por terem relação com Belém, onde se realizou o congresso. Outros mais, talvez até de uma maneira inconsciente, podem ter tido sua atenção despertada para um interesse efetivo sobre o tema a partir das palestras e das deliberações do congresso. Sobre todos pairava a figura importante de Pedro Escudero (1887-1963), médico argentino, criador do Instituto Nacional de Nutrição naquele país, considerado o pioneiro nos estudos de nutrição na América Latina e com quem vários haviam estudado ou trabalhado, dentre os quais podemos destacar Pedro Borges e o próprio Josué de Castro (Bizzo, 2012, p.86).

Se observarmos mais detalhadamente, o tema "alimentação" - de interesse particular do organizador do congresso, o doutor Pedro Borges - permearia pelo menos mais um tema oficial, qual seja o da mortalidade infantil. Do mesmo modo, as plenárias extraordinárias também tangenciaram o tema ao falar sobre tuberculose, bem como as palestras resultando em deliberações ao final do evento: conforme o relatório dos trabalhos apresentados, várias sugestões foram propostas relacionadas aos temas oficiais, considerando a realidade local dos estados representados e as nosologias abordadas no evento. O próprio Josué de Castro, 
ao fazer um balanço sobre o congresso, destaca essa preocupação com a alimentação na Amazônia e a necessidade imediata de coordenar esforços para melhorá-la, plenamente em concomitância com as diretrizes internacionais para a "nova ciência da nutrição", surgidas na década de 1930 (Bizzo, 2012, p.27).

Talvez por ter sido um evento pioneiro ou para demonstrar o "entrelaçamento de diferentes saberes e âmbitos institucionais" (Nunes, 2010, p.157), o primeiro Congresso Médico Amazônico abriu espaço para uma programação cultural de permeio às atividades científicas. Após o encerramento das sessões no Theatro da Paz, o governo do estado promoveu uma "reunião da Arte e do Pensamento" no salão principal da biblioteca pública em homenagem aos participantes do congresso. Uma exposição com pinturas e esculturas, juntamente com a apresentação de músicos e de poetas, serviria como uma amostra da produção artística paraense, numa verdadeira "Festa da Beleza e Emoção", como frisou a reportagem do jornal $A$ Folha do Norte (As derradeiras..., 17 ago. 1939, p.5).

Outra atividade extracientífica relacionada ao congresso foi a homenagem da Academia Paraense de Letras à sua congênere amazonense, considerando que três componentes da delegação daquele estado eram membros da Academia Amazonense de Letras: Adriano Jorge, presidente do "sodalício amazonense", Araújo Lima e Ramayana de Chevalier. Sob o comando de Deodoro de Mendonça, presidente da Academia Paraense e secretário de governo, um jantar foi servido nos salões do Grande Hotel, quando oradores de ambas as casas se fizeram ouvir, sendo o evento retransmitido pela Rádio Clube do Pará (A academia..., 18 ago. 1939).

\section{O saldo do congresso}

Ressaltando a importância do tema "alimentação" dentro do primeiro Congresso Médico Amazônico, por proposição do doutor Araújo Lima, um dos componentes da delegação do estado do Amazonas, foi encaminhado ao prefeito de Belém, doutor Abelardo Conduru, a criação de uma Diretoria de Alimentação, "núcleo primário a se ampliar posteriormente por todo o estado" (Borges, Milet, Azevedo, 1939, p.13).

O projeto saiu do papel. O prefeito Abelardo Conduru criou a Diretoria de Alimentação Pública Municipal (O banquete..., 17 ago. 1939) sob a direção de Pedro Borges, que viajou em missão especial da prefeitura para estudos e pesquisas na Argentina com o objetivo de "estudar as modelares organizações científicas e sociais de alimentação coletiva, ali existentes, a fim de pôr em execução o recente decreto do prefeito" (Em missão..., 31 out. 1939). Um prédio foi construído no terreno do Hospital da Santa Casa para o que seria o ponto de partida para um futuro Instituto de Nutrição da Amazônia (Figura 3). 


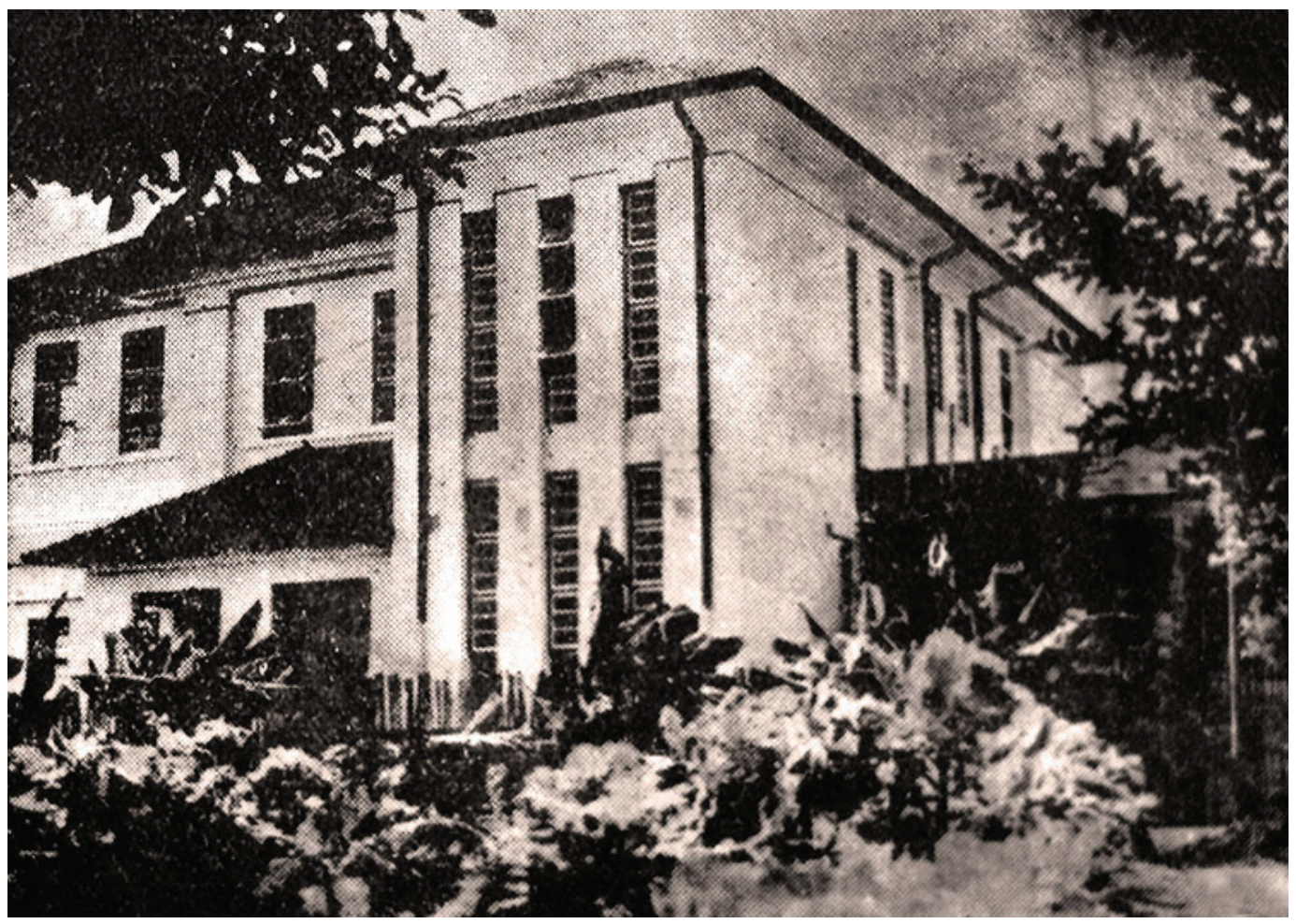

Figura 3: Edifício da Diretoria de Alimentação da Prefeitura, anexo ao Hospital da Santa Casa (Pará llustrado, n.103, 24 jan. 1942, p.16)

O ano era 1943. O Brasil entrara na guerra. O domínio japonês da Ásia impedia a utilização da borracha produzida na Malásia para a indústria bélica aliada. Era necessário reativar os seringais nativos da Amazônia e, consequentemente, intensificar a migração nordestina para ali trabalhar. Os movimentos de migração de trabalhadores nordestinos para a Amazônia trouxeram grande impacto no imediato momento dos empreendimentos e na posterior permanência desses grupos sociais na região com suas tradições e experiências (Lacerda, 2010). Desde os primeiros anos, isso demandaria uma estrutura para cuidar da saúde desses homens, principalmente, um hospital de retaguarda em Belém. E qual a estrutura - quase pronta - que poderia ser adaptada para funcionar como hospital? O prédio de Pedro Borges! Então, "o Sesp [Serviço Especial de Saúde Pública] tomou conta de tudo, reformou, ampliou e colocou em funcionamento o hospital 'Carlos Chagas'. ${ }^{8}$ Pedro Borges ficou no espaço, com um trabalho de mais de três anos completamente perdido" (Meira, 1986, p.320).

De fato, o debate acerca do legado do congresso confirma esse momento em que os saberes científicos e médicos eram chamados para os desafios quanto às intervenções estatais na Amazônia. Em 1942, a instalação do Serviço Especial de Saúde Pública (Sesp), aumentando a atuação estatal na região, representaria parte do acúmulo desse debate. A proposta para instalação do Instituto Internacional da Hileia Amazônica e, anos mais tarde, a criação da Superintendência do Plano de Valorização Econômica da Amazônia (SPVEA), em 1953, 
sinalizavam para disputas e interesses nacionais e estrangeiros pela região durante o Estado Novo e no período desenvolvimentista (Andrade, 2015).

\section{Considerações finais}

Um congresso voltado para discussão de temas médicos deixaria sua marca em uma área de atuação então pouco usual na medicina praticada na Amazônia, a nutrição, embora se soubesse da sua relação com várias doenças, particularmente a tuberculose, amplamente estudada naqueles anos. Essa linha de conhecimento acabaria se desvinculando das áreas de atuação da medicina, tornando-se autônoma a partir dos anos 1970, com a criação dos cursos de graduação em nutrição. Mas merece registro esse momento acontecido em Belém, pela presença e participação de nomes da maior importância nos estudos iniciais sobre a alimentação no congresso.

Esse fato foi perfeitamente "diagnosticado" pela imprensa. Em artigo para a Folha do Norte, Laudelino Nunes, ao fazer um resumo do evento e tecer suas considerações, assim conclui: "o Congresso Médico, tratando de alimentação na Amazônia, deve ter adotado medidas práticas para corrigir, ao menos em parte, o nosso regime alimentar, quantitativa e qualitativamente falho" (A rapidez..., 27 set. 1939).

Por ter sido uma iniciativa pioneira, para uma sociedade ávida por novidades, ao menos as sessões de inauguração e de encerramento do congresso contaram com a presença de representantes dos mais diversos grupos sociais: "Nas cadeiras destinadas à assistência, grupos de distintas famílias da nossa sociedade, cavalheiros, comerciantes, funcionários públicos federais e estaduais, acadêmicos e estudantes das escolas superiores, permanecendo em pé, por falta de lugares, avultado número de pessoas" (Encerramento..., 17 ago. 1939). Assim, entendemos o primeiro Congresso Médico Amazônico como emblema da comunicação científica, sinalizando a legitimação de suas redes de interações, relações com a imprensa local e nacional e com a sociedade, em busca de reconhecimento social.

A capacidade da organização de congressos pela classe médica da Amazônia não se confirmaria de imediato. Embora pensado para ser realizado bianualmente e com rotatividade das sedes, já tendo Manaus como local escolhido para o evento de 1941 (Borges, Milet, Azevedo, 1939), o Congresso Médico Amazônico seguiria uma trajetória claudicante. A segunda edição só se realizaria em 1956 e em Macapá. O evento adquiriu sua regularidade bienal a partir dos anos de 1980, persistindo até os dias de hoje, com sede sempre em Belém e com uma proposta bastante diferente dos primeiros tempos. A efetiva capacidade da ação da saúde pública na região igualmente não vivenciaria realidades muito diferentes a partir de 1940, ainda que a inclusão do pressuposto da alimentação revelasse um novo paradigma ao olhar dos doutores para as condições de pobreza e miséria das populações amazônidas.

\section{NOTAS}

${ }^{1}$ A Sociedade Médico-Cirúrgica do Pará (SMCP) foi fundada em 12 de julho de 1914 após algumas reuniões preliminares e instalada em 15 de agosto do mesmo ano. Reunindo a elite médica de Belém, teve papel 
importante nos seus primeiros tempos, como na criação da Faculdade de Medicina e Cirurgia do Pará. Embora ainda existente, com o passar dos anos e a diversificação/especialização da profissão médica foi perdendo seu poder (ver Miranda, Abreu Jr., 2014).

${ }^{2}$ Foram estes os representantes estaduais participantes do congresso e os congressistas locais: Amazonas: Adriano Augusto de Araújo Jorge, Araújo Lima, Jorge Fernandes, João de Paula Gonçalves, Walmiki Ramayana e Souza de Chevalier. Ceará: Alberto Leite, Antonio Bello da Motta, Arthur Silva Novaes, Cesar Cals de Oliveira, Jurandyr Moraes Picanço, Pedro Augusto de Araújo Sampaio, Virgílio de Useda, Walter Frota de Magalhães Porto, Walter de Moura Cantidio. Maranhão: Alfredo Duailibe, Antônio Pires Ferreira, Edison Netto Teixeira, José da Silva Novaes, Odilon Soares, Odorico Amaral de Matos, Clodomir Teixeira Millet. Paraíba: João Fernandes Barbosa. Pernambuco: Rinaldo Azevedo. Distrito Federal: Dante Oliveira Costa e Josué Apolônio de Castro. Pará: Acatauassu Nunes Filho, Affonso Rodrigues Filho, Arthur França, Auzier Bentes, Celso Malcher, Emygdio Pedreira, Ferdinando Santos, Froylan Barata, Garcia Filho, Henrique Esteves, Hermínio Pessoa, Higino Silva, Jaime Aben-Athar, José de Souza Macedo, José Maria Chaves, Lauro de Magalhães, Luiz Araújo, Orlando Lima, Oscar Miranda, Pedro Borges, Pedro Rosado, Prisco dos Santos, Porto de Oliveira, Nizomar Azevedo. Pelo Rotary: Adriano Pereira Guimarães e Amadeu Dourado; delegado do Instituto Oswaldo Cruz junto ao congresso: Evandro Chagas.

${ }^{3}$ Jornal de Joinville (SC), que reproduz telegrama enviado pela organização do congresso ao interventor de Santa Catarina, Nereu Ramos.

${ }^{4}$ João Peregrino Júnior da Rocha Fagundes, jornalista, médico, contista e ensaísta, nasceu em Natal (RN), em 1898, e faleceu no Rio de Janeiro (RJ), em 1983. Por divergências com o diretor do colégio em Natal, mudou-se para Belém, onde estudou e trabalhou na imprensa entre 1914 e 1920. Após ter iniciado o curso médico em 1919, na recém-criada Faculdade de Medicina e Cirurgia do Pará (Miranda, Abreu Jr., 2009, p.40), partiu no ano seguinte para o Rio de Janeiro, onde concluiu o curso médico em 1929 (Peregrino Jr., [20--?]).

${ }^{5}$ Manoel Dias de Abreu, paulista nascido em 1892, formou-se em medicina no Rio de Janeiro em 1913. Após estudos na Europa, onde dedicou-se à radiologia, retornou ao Brasil em 1922. Preocupado com as altas taxas de tuberculose, inventou um método barato para o diagnóstico em massa de doenças pulmonares, que a partir de 1939 recebeu o nome oficial de abreugrafia (Silveira, 24 dez. 2009; Fioravantti, fev. 2015).

${ }^{6}$ O Serviço de Estudos de Grandes Endemias (Sege) foi criado por Evandro Chagas, filho do cientista Carlos Chagas em 1937. Tal instituição estava inserida nos debates do modelo de saúde pública que enfatizava o combate às doenças endêmicas em uma relação direta com as denúncias feitas no início do século pelo movimento sanitarista baseado no Instituto Oswaldo Cruz (IOC) (Barreto, 2012; Fonseca, 2007).

${ }^{7}$ Oficialmente os temas foram assim definidos: Etiologia, Diagnóstico e profilaxia da lepra; O problema da alimentação na Amazônia; Formas amazônicas do paludismo; e Mortalidade infantil em Belém (Primeiro Congresso..., 1939).

${ }^{8}$ Aí há um engano do autor: o hospital chamava-se Evandro Chagas. Posteriormente o Sesp devolveu o edifício à prefeitura, que o transformou no Pronto Socorro Municipal de Belém, hoje Pronto Socorro Mário Pinotti.

\section{REFERÊNCIAS}

A ACADEMIA...

A Academia Paraense de Letras homenageia a sua congênere do Amazonas. Folha do Norte, p.4. 18 ago. 1939.

AINDA O CONGRESSO...

Ainda o Congresso Médico Amazônico. Folha do Norte, p.6. 7 set. 1939.

A INSTALAÇÃO...

A instalação do primeiro Congresso Médico da

Amazônia. Folha do Norte, p.1-2. 11 ago. 1939.

ALMEIDA, Marta de.

Congresso e exposições científicas: tema e fontes para a história. In: Heizer, Alda; Videira, Antonio Augusto Passos (Org.). Ciência, civilização e República nos trópicos. Rio de Janeiro: Mauad X; Faperj. p.197-208. 2010.

ALMEIDA, Marta de.

Circuito aberto: ideias e intercâmbios médicocientíficos na América Latina nos primórdios do século XX. História, Ciências, SaúdeManguinhos, v.13, n.3, p.733-757. 2006.

ANDRADE, Manuel Correa de. Josué de Castro: o homem, o cientista e seu tempo. Estudos Avançados, v.11, n.29, p.169-194. 1997.

ANDRADE, Manuel Correa de et al. Josué de Castro e o Brasil. São Paulo: Editora Fundação Perseu Abramo. 2003. 
ANDRADE, Rômulo de Paula.

O pobre solo do celeiro do mundo:

desenvolvimento florestal e combate à fome na Amazônia. Estudos Históricos, v.28, n.56, p.285304. 2015.

ANDRADE, Rômulo de Paula.

"Conquistar a terra, dominar a água, sujeitar a floresta": Getúlio Vargas e a revista "Cultura Política" redescobrem a Amazônia, 1940-1941. Boletim do Museu Paraense Emílio Goeldi. Ciências Humanas, v.5, n.2, p.453-468. 2010.

ANDRADE, Rômulo de Paula; HOCHMAN, Gilberto.

O Plano de Saneamento da Amazônia. História, Ciências, Saúde - Manguinhos, v.14, supl., p.257277. 2007.

A RAPIDEZ...

A rapidez fugaz do $1^{\circ}$ Congresso Amazônico. Folha do Norte, p. 5.27 set. 1939.

AS DERRADEIRAS...

As derradeiras homenagens aos membros do $1^{\circ}$ Congresso Médico Amazônico. Folha do Norte, p.1. 17 ago. 1939.

AUTRAN, Arthur.

Líbero Luxardo: 100 anos. Belém: Fundação Cultural Tancredo Neves; Governo do Estado do Pará. 2008.

BARRETO, Danielle Cristina dos Santos. Uma trajetória familiar na ciência: Evandro Chagas (1905-1940) e o estudo das endemias rurais no Brasil. Dissertação (Mestrado em História das Ciências e da Saúde) - Fundação Oswaldo Cruz, Rio de Janeiro. 2012.

BIZZO, Maria Letícia Galluzzi.

Agências internacionais e agenda local: atores e ideias na interlocução entre nutrição e país (1932-1964). Tese (Doutorado em História das Ciências e da Saúde) - Fundação Oswaldo Cruz, Rio de Janeiro. 2012.

BORGES, Pedro; MILET, Clodomir; AZEVEDO, Rinaldo de.

Primeiro Congresso Médico Amazônico: relatório. Belém: Oficinas Gráficas do Instituto Lauro Sodré. 1939.

BOURDIEU, Pierre.

A ilusão biográfica. In: Ferreira, Marieta de Moraes; Amado, Janaína. Usos e abusos da história oral. Rio de Janeiro: Editora FGV. p.183191. 2006.

CÂMARA MUNICIPAL...

Câmara Municipal de Manaus. Adriano Augusto de Araújo Jorge. Disponível em: <http://www. cmm.am.gov.br/adriano-augusto-de-araujojorge/>. Acesso em: 19 fev. 2019. [1975?]
CASTRO, Fábio Fonseca de.

A cidade sebastiana: Era da Borracha, memória e melancolia numa capital da periferia da modernidade. Belém: Edições do Autor. 2010.

COMO DECORREU...

Como decorreu a sessão de encerramento do primeiro Congresso Médico da Amazônia. Estado do Pará, p.5. 16 ago. 1939.

CONGRESSO MÉDICO....

Congresso Médico Amazônico. Folha do Norte, p.10. 13 jul. 1939.

\section{CORRESPONDÊNCIA...}

Correspondência oficial. Folha Vespertina, p.5. 8 ago. 1939.

COSTA, Antônio Maurício.

Cidade dos sonoros e dos cantores: estudos sobre a era do rádio a partir da capital paraense. Belém: Imprensa Oficial do Estado. 2015.

COSTA, Dante.

Saúde, alimentação e pobreza na Amazônia. Rio de Janeiro: Serviço de Documentação/Ministério da Educação e Cultura. 1965.

COSTA, Dante.

Bases da alimentação racional: orientação para o brasileiro. São Paulo: Companhia Editora Nacional. 1938.

CUNHA, Euclides da.

À margem da história. São Paulo: Martins Fontes. 1999.

DAOU, Ana Maria.

A belle époque amazônica. Rio de Janeiro: Jorge Zahar. 2004.

EM MISSÃO...

Em missão a Argentina o Doutor Pedro Borges. Folha do Norte, p.2. 31 out. 1939.

ENCERRAMENTO...

Encerramento do $1^{\circ}$ Congresso Médico da Amazônia. Estado do Pará, p.3. 17 ago. 1939.

ENCERRA-SE..

Encerra-se hoje o $1^{\circ}$ Congresso Médico Amazônico. Folha do Norte, p.3. 15 ago. 1939.

FIGUEIREDO, Aldrin Moura de.

Páginas antigas: uma introdução à leitura dos jornais paraenses, 1822-1922. Margens, v.2, n.3, p.245-266. 2005.

FIORAVANTTI, Carlos.

Memória: retrato dos pulmões. Pesquisa Fapesp, n.228, p.90-91. fev. 2015.

FONSECA, Cristina M. Oliveira de.

Saúde no Governo Vargas (1930-1945): dualidade institucional de um bem público. Rio de Janeiro: Editora Fiocruz. 2007. 
FROTA, Jorge Washington da Silva.

Educação e alimentação: ideias sociais, políticas e pedagógicas na obra de Dante da Costa. Dissertação (Mestrado em Educação) - Universidade Federal do Ceará, Fortaleza. 2011.

HENRIQUE, Márcio Couto; AMADOR, Luiza Helena Miranda.

Da Belle Époque à cidade do vício: o combate à sífilis em Belém do Pará, 1921-1924. História, Ciências, Saúde - Manguinhos, v.23, n.2, p.359378. 2016.

KRUGER, Marcos Frederico.

À margem de Euclides. In: Chevalier, Ramayana. No circo sem teto da Amazônia. Manaus: Editora Valer; Governo do Estado do Amazonas. 2001.

KUHLMANN JR., Moysés.

Congressos profissionais do século XIX e início do século XX: ciência e política. In: Heizer, Alda; Videira, Antonio Augusto Passos (Org.). Ciência, civilização e República nos trópicos. Rio de Janeiro: Mauad X; Faperj. p.179-195. 2010.

LACERDA, Franciane Gama.

Migrantes cearenses no Pará: faces da sobrevivência, 1889-1916. Belém: Açaí; Centro de Memória da Amazônia/PPHIST-UFPA. 2010.

LEVI, Giovanni.

Usos da biografia. In: Amado, Janaína; Ferreira, Marieta de M. (Org.). Usos e abusos da história oral. Rio de Janeiro: FGV. p.167-182. 1996.

LUCA, Tania Regina de.

História dos, nos e por meio dos periódicos. In: Pinsky, Carla Bassanezi (Org.). Fontes históricas. São Paulo: Contexto. p.111-154. 2005.

MACEDO, Souza.

$1^{\circ}$ Congresso Médico da Amazônia: comentários para as Folhas. Folha do Norte, p.179-195. 14 jul. 1939.

MEIRA, Clóvis Olinto de Bastos.

Pedro Lago da Costa Borges. In: Meira, Clóvis Olinto de Bastos. Médicos de outrora no Pará. Belém: Grafisa. 1986.

MIRANDA, Aristoteles Guilliod de; ABREU JR., José Maria de Castro.

Razões do esquecimento: em busca dos vestígios do Sindicato Médico Paraense. Revista Panamazônica de Saúde, v.6, n.2, p.11-21. 2015.

MIRANDA, Aristoteles Guilliod de; ABREU JR. José Maria de Castro.

A fundação da Sociedade Médico-Cirúrgica do Pará. Revista Pan-amazônica de Saúde, v.5, n.1, p.11-18. 2014.
MIRANDA, Aristóteles Guilliod de; ABREU JR., José Maria de Castro.

Memória histórica da Faculdade de Medicina e Cirurgia do Pará, 1910-1950: da fundação à federalização. Belém: Edufpa. 2009.

MUNIZ, Érico Silva.

A ciência e a mandioca: os hábitos alimentares na Amazônia e a obra de Dante Costa. Revista Estudos Amazônicos, v.11, n.2, p.56-80. 2015.

NOTAS...

Notas mundanas: um almoço íntimo para Dante Costa. Folha do Norte, p.2. 18 ago. 1939.

NOTÁVEL CIENTISTA...

Notável cientista em trânsito por Belém visita o Instituto de Patologia e assiste ao Congresso Médico. Folha do Norte, p.3. 14 ago. 1939.

NOTÍCIAS...

Notícias do Pará. Jornal do Brasil, p.13. 15 ago. 1939.

NUNES, Sérgio.

I Congresso Brasileiro de Geografia (1909): um "festival científico" no início do século XX. In: Heizer, Alda; Videira, Antonio Augusto Passos (Org.). Ciência, civilização e República nos trópicos. Rio de Janeiro: Mauad X; Faperj. p.157-177. 2010.

O BANQUETE...

O banquete de despedida, oferecido pela

Prefeitura, aos delegados do $1^{\circ}$ Congresso

Médico Amazônico. Folha Vespertina, p.4. 17 ago. 1939.

O BRASIL...

O Brasil pelo telégrafo. O Imparcial, p.4. 17 ago. 1939.

O PRIMEIRO CONGRESSO...

O primeiro Congresso Médico Amazônico: telegramas recebidos. Folha do Norte, p.1. 12 ago. 1939.

PACHECO, Agenor Sarraf.

En el corazón de la Amazonía: identidades, saberes e religiosidades no regime das águas marajoaras. Tese (Doutorado em História Social) - Pontifícia Universidade Católica de São Paulo, São Paulo. 2009.

PARABÉNS...

Parabéns, Pedro Borges. Folha do Norte. p.9. 13 ago. 1939.

PARA O CONGRESSO...

Para o Congresso Médico. Correio da Manhã, p.9. 15 ago. 1939.

PEREGRINO JR., João.

Academia Brasileira de Letras. Perfil do acadêmico. Biografia. Disponível em: <http:// www.academia.org.br/academicos/peregrinojunior>. Acesso em: 12 fev. 2019. [20--?]. 
PONTES, Joyce Karoline Pinto Oliveira; PONTES, Aldrin Bentes.

O pensamento social da Amazônia no olhar do intelectual Araújo Lima. Relem: Revista Eletrônica Mutações, v.6, p.39-47. Disponível em: $<$ www.periodicos.ufam.edu.br/relem/article/ view/917/904>. Acesso em: 18 fev. 2019. jul.-dez. 2015.

\section{PRIMEIRO CONGRESSO...}

Primeiro Congresso Médico Amazônico: as teses que serão apresentadas. Folha do Norte, p.2. 9 ago. 1939.

PRIMEIRO CONGRESSO...

Primeiro Congresso Médico Amazônico. Estado do Pará, p.4. 28 jul. 1939.

PRIMEIRO CONGRESSO...

Primeiro Congresso Médico Amazônico: o apoio. Estado do Pará, p.5. 16 jul. 1939a.

PRIMEIRO CONGRESSO...

Primeiro Congresso Médico da Amazônia: palavras proferidas. Folha do Norte, p.10. 16 jul. 1939b.

PRIMEIRO CONGRESSO...

Primeiro Congresso Médico da Amazônia. Folha do Norte, p.2. 14 jul. 1939.

PRIMEIRO CONGRESSO...

Primeiro Congresso Médico Amazônico: 20:000\$000 como auxilio às despesas. Folha Vespertina, p.3. 10 jul. 1939.

PRIMEIRO CONGRESSO...

Primeiro Congresso Médico Amazônico. Folha do Norte, p.6. 9 jul. 1939.

PRIMEIRO CONGRESSO...

Primeiro Congresso da Amazônia. Folha do Norte, p.1. 7 jul. 1939.

PRIMEIRO CONGRESSO...

Primeiro Congresso Médico Amazônico. A Notícia, p.1. 28 jun. 1939.

PRIMEIRO CONGRESSO..

Primeiro Congresso Médico do Interior. Folha do Norte, p.2. 24 jan. 1939.

\section{PRIMEIRO CONGRESSO...}

Primeiro Congresso Médico Amazônico. Belém:

Oficinas Gráficas do Instituto Lauro Sodré. 1939.

SÁ, Dominichi Miranda de.

A ciência como profissão: médicos, bacharéis e cientistas no Brasil, 1895-1935. Rio de Janeiro: Editora Fiocruz. 2006.

SANJAD, Nelson.

Exposições internacionais: uma abordagem historiográfica a partir da América Latina. História, Ciências, Saúde - Manguinhos, v.24, n.3, p.785-826. 2017.

SARGES, Maria de Nazaré.

Belém, riquezas produzindo a Belle Époque: 18701912. Belém: Paka-Tatu. 2000.

SILVEIRA, Igor.

Manoel de Abreu: o inventor. Estado de Minas, p.16. 24 dez. 2009.

\section{SOCIEDADE...}

Sociedade Médico-Cirúrgica do Pará. Folha do Norte, p.6. 20 jan. 1939.

SOUZA, Roseane Silveira de.

Histórias invisíveis do Theatro da Paz. Belém: Paka-Tatu. 2010.

UM MÉDICO...

Um médico paraense fala ao "Correio da Noite" sobre o Congresso Médico de Belém. Folha do Norte, p.3. 26 jul. 1939.

VASCONCELOS, Francisco de Assis Guedes de. A ciência da nutrição em trânsito: da nutrição e dietética à nutrigenômica. Revista de Nutrição de Campinas, v.23, n.6, p.935-945. 2010.

VERIANO, Pedro.

Cinema no tucupi. Belém: Secult. 1999.

VIEIRA, Ruth; GONÇALVES, Fátima.

Ligo o rádio para sonhar: a história do rádio no Pará. Belém: Prefeitura de Belém. 2003.

WEINSTEIN, Bárbara.

A borracha na Amazônia: expansão e decadência, 1850-1920. São Paulo: Hucitec; Edusp. 1993.

\section{$\rightarrow \rightarrow \rightarrow<<<$}

